\title{
BIODIVERSITY AND GEOGRAPHY
}

\author{
MiCHAEL RAUSCHER \\ EDWARD B. BARBIER
}

CESIFO WORKING PAPER NO. 2022

CATEGORY 8: RESOURCES AND ENVIRONMENT

JUNE 2007

An electronic version of the paper may be downloaded

- from the SSRN website:

- from the RePEc website:

www.SSRN.com

www.RePEc.org

- from the CESifo website: www.CESifo-group.de 


\title{
BIODIVERSITY AND GEOGRAPHY
}

\begin{abstract}
The paper combines an economic-geography model of agglomeration and periphery with a model of species diversity and looks at optimal policies of biodiversity conservation. The subject of the paper is "natural" biodiversity, which is inevitably impaired by anthropogenic impact. Thus, the economic and the ecological system compete for space and the question arises as to how this conflict should be resolved. The decisive parameters of the model are related to biological diversity (endemism vs. redundancy of species) and the patterns of economic geography (centrifugal and centripetal forces). As regards the choice of environmental-policy instruments, it is shown that Pigouvian taxes do not always establish the optimal allocation.
\end{abstract}

JEL Code: Q56, Q57, Q58, R12, R14, R23.

Keywords: biodiversity, new economic geography, agglomeration, species redundancy vs. endemism, environmental regulation.

\author{
Michael Rauscher \\ Faculty of Economics \\ University of Rostock \\ Ulmenstr. 69 \\ 18051 Rostock \\ Germany \\ michael.rauscher@uni-rostock.de
}

\author{
Edward B. Barbier \\ Department of Economics and Finance \\ University of Wyoming \\ Department 3985 \\ Ross Hall 123 \\ Laramie, WY 82071 \\ USA \\ ebarbier@uwyo.edu
}




\title{
Biodiversity and Geography*
}

\author{
Michael Rauscher
}

Edward B. Barbier

\section{Introduction}

This paper uses recent advances in economic geography models of international trade and factor mobility to assess the incentives for regions to agglomerate economic activity versus preserve biodiversity. We consider a world consisting of two regions, home and foreign. Both regions contain an economic system in which a manufacturing industry, characterized by increasing returns and monopolistic competition, as well as an ecological system containing biodiversity (species richness), which is a global public good. The economic and the ecological system compete for space. Increased economic activity results in both loss of species richness and of the total biomass of each species population. From this trade-off, the question arises where economic activities should be performed and where biodiversity should be preserved. The next question then is by which policy instruments an optimal spatial allocation of economic activities and natural habitat can be achieved.

We use a model of the new-economic-geography type to address these questions. New economic geography was introduced by Krugman (1991) in his seminal book and has resulted in a large variety of models addressing various questions related to spatial patterns of economic activities involving processes of agglomeration and dispersion. See Fujita et al. (1999), Neary (2001), and Baldwin et al. (2003) for overviews. Common to all these models is the assumption a monopolistically competitive market structure, usually modeled à la Dixit and Stiglitz (1977), and "iceberg" transportation costs, i.e. the assumption that a certain fraction of a traded commodity "melts away" during transport. ${ }^{1}$ We use this approach, but make some simplifying

\footnotetext{
The authors thank John Tschirhart and the participants of the 2007 conference of Committee of Environmental and Resource Economics of the "Verein für Socialpolitik" for helpful comments and suggestions. Michael Rauscher wishes to thank the Centre of Advanced Study (CAS) at the Norwegian Academy of Science and Letters for its support and hospitality. Parts of the paper were written presented in seminars during a stay at CAS in 2006 as part of the project "Environmental Economics: Policy Instruments, Technology Development, and International Coordination". The authors bear full responsibility for errors and shortcomings.

1 Iceberg transportation costs are generally attributed to Samuelson (1952), but the concept is much older and dates back to Thünen $(1842$, p. 16), who developed a theory of "central places" and assumed about transport costs that a fraction of the grain transported from the rural area to the city, the "central place", is eaten by the horses pulling the carts.
} 
assumptions. Unlike in most other new-economic-geography models, we assume that there is only one factor of production. Moreover, we assume quasilinear preferences such that our model is essentially partial equilbrium.

As regards biodiversity, the paper addresses the issue of "natural" biodiversity, or, as Eichner and Tschirhart (2007) put it: people have a preference for "naturalness". The starting point is an ecological model that is based on an "as if" optimization model. Species act as if they want to maximize their net energy. See Pethig and Tschirhart (2001) for the basic argument. The carrying capacity of ecological systems is negatively affected by economic activities such as human habitation and industrial production. This establishes the link between the economic and the ecological system and generates a trade-off between the objectives of satisfying material needs and conserving biodiversity. Anthropogenic impact via habitation, production, and consumption inevitably impairs natural habitats and reduces natural biodiversity. Of course, there are some economic activities that may actually increase biodiversity, e.g. in organic farming, but they are not the subject of this paper. We exclusively deal with "natural" biodiversity. The question then is how to resolve the conflict between material wants and the preservation of pristine ecosystems. Is it better to concentrate ecologically harmful activities in one region and leave the other region untouched as a protected area or should one distribute economic activities more evenly in space? It will be shown that the answer to this question depends on the properties of the ecosystems under consideration. To this end, we employ the concepts of endemism and redundancy. Endemic species occur in only one region, whereas redundant species occur in both regions. The degree of endemism versus redundancy will be crucial for the solution of the conflict between economic activities and biodiversity conservation.

The literature on spatial aspects of the economy-environment conflict is small, particularly if the new-economic-geography contributions are concerned. Siebert's (1985) handbook article was written before the emergence of the new economic geography. Kanbur et al. (1995) model space as a continuous variable and look at the impact of environmental regulation on the location of polluting industries. Rauscher (2000) and Pflüger (2001) address environmental issues in a genuine new-economic-geography setting, but do not address issues related to biodiversity issues. Some ecology-economic models have analyzed the spatial interdependence of landscapes (Bockstael 1996; Koskela and Ollikainen (2001) or renewable resource models that include a spatial diffusion process (Brock and Xepapadeas 2006; Smith et al. 2007; Sanchirico and Wilen 2005 ) in a wide class of environmental problems, from biological invasions to natural reserve creation to provision of ecological services. But these models typically do not consider the centrifugal-centripetal effects of new economic geography to analyze the optimal spatial allocation of economic activity as opposed to biodiversity conservation. Such effects have been long recognized in ecology; e.g., Okubo (2001) notes that biological resources are distributed in space under analogous forces promoting "spreading" or "concentrating", and these processes 
along with inter-specific competition determine the spatial patterns exhibited by species. ${ }^{2}$ While recognizing the importance of this spatial dimension, recent contributions to the economics of biodiversity preservation have focused on a unified ecological, economic and genetic approach to modelling the valuation problem rather than considering the opposing centrifugal-centripetal forces influencing the location and size of optimal habitat relative to economic activity (Brock and Xepapadeas 2003; Metrick and Weitzman 1998). To our knowledge, our paper is the first contribution that develops a new-economic-geography model to analyze this key issue in biodiversity conservation.

The paper is organized as follows. The next section presents the essentials of a simple neweconomic-geography model with two symmetric regions and links it to an ecological model of species richness and biodiversity. Section 3 looks at a variant of the model where households are mobile, but factors of production are region-specific. It will be seen that the laissez-faire equilibrium is characterised by dispersion, i.e. housholds locate such that they are equally distributed across regions. Biodiversity considerations, however, may favour concentration of settlements in one of the two regions and we discuss policy measures inducing the corressponding change in location patterns. It will be seen that Pigouvian taxes are useful to etsablish the optimum. Section 4 will be devoted to case where not only people but also factors of production are mobile. We call this the mobile-capital model since we assume that factors nd factor owners can locate in different regions. Laissez faire leads to agglomeration in this case, i.e. factors and households tend to concentrate in the same region. If biodiversity considerations are taken into account, however, a more equal distribution of economic activities across regions may be preferable. It is shown that taxes alone cannot establish the dersired allocation of factors and households, but a combination of command-and-control regulation may do the job. Section 5 then addresses a scenario where factors and factor owners cannot be separated from each other geographically. We call this the mobile-workers model: the worker lives in the region in which the factor she is endowed with is employed. Again, the laissez-faire equilibrium is agglomeration and the biodiversity objective may call for a more equal distribution of factors and factor owners. In this case, taxes does not support the desired allocation and the policy maker has to take recourse to command and control. Section 6 summarizes.

2 Interestingly, the analogy between these forces in spatial ecology and the typical agglomeration versus dispersion effects in new economic geography was noted by early developments of core-periphery models. For example, Fujita et al. (1999, ch. 6) cite the analogy between the stabilization properties observed in their core-periphery models and the Turing effect in spatial ecology, which implies that an initially spatially homogeneous state, such as a uniform distribution of species, can be transformed into a stable but patterned state under perturbations induced by diffusion. 


\section{The Economic-Ecological Model}

Let us consider a world consisting of two regions, home and foreign. We identify all variables of the foreign region by asterisks. Initially, it is assumed that both regions are identical. Preferences and production technologies are the same at home and abroad. Assume that the total population in these two regions is 1 , of which $N$ live in the home region and (1-N) abroad. All households are identical and factor ownership is equally distributed across the households such that each household owns one unit of the factor. Let $y$ and $y^{*}$ denote the factor incomes of domestic and foreign households, respectively. Moreover, each household inelastically supplies one unit of a numéraire good. Thus, gross income of a representative domestic household is $1+y$. In addition, we model a transfer across regions. Let us assume that domestic households are taxed at rate $t$ and that the tax revenue is redistributed lump-sum to all domestic and foreign households. Thus the net tax payment of a domestic household is $(1-N) t$ and the transfer income accruing to a foreign household is $t N$. The tax rate may be negative, denoting a transfer in the opposite direction, i.e. from foreign to home households. But since the model is symmetric anyway, the following analysis will be confined to positive tax rates. A representative domestic household's budget constraint is

$$
\int_{0}^{n} p(i) c(i) d i+\int_{0}^{n^{*}} \theta p *(i) m(i) d i+x=1+y-(1-N) t .
$$

where the right-hand side is income and the right-hand side expenditure. $x$ is the consumption of the numéraire good, $c(i)$ is consumption of a domestic variety, $m(i)$ denotes the imported and consumed quantity of a foreign variety, and $\theta$ is the "iceberg" transportation cost mark-up. Thus $p(i)$ and $p^{*}(i)$ are the prices of domestic and foreign goods, respectively, and $n$ and $n^{*}$ measure product variety. With a transfer income $N t$, the budget constraint of a representative foreign household is then

$$
\int_{0}^{n} p^{*}(i) c^{*}(i) d i+\int_{0}^{n^{*}} \theta p(i) m^{*}(i) d i+x^{*}=1+y^{*}+N t .
$$

Note that we futher simplify the basic economic geography models suggested by Baldwin et al (2003). In our model, there is only one factor of production and the numéraire good is not produced by means of scarce factors but "falls from heaven", albeit in limited supply. This, together with the assumption of a very lean utility function (see the following paragraph) simplifies the derivation of results considerably, but also affects the qualitative results, particularly in the scenario of mobile workers. This will be discussed indetail in Section 5.

Utility is assumed to be quasilinear such that, for the home household, we have

$$
u=\frac{1}{\gamma}\left(\int_{0}^{n} c(i)^{\gamma} d i+\int_{0}^{n^{*}} m(j)^{\gamma} d j\right)+x+\omega\left(d\left(s, s^{*}\right)\right) .
$$


$\gamma \in(0,1)$ is a measure of substitutability such that $\gamma=1$ denotes perfect substitutes and $\gamma=0$ an elasticity of substitution being unity. The specification of utility derived from consumption is even simpler than that in Pflüger $(2001,2004)$, who took the logarithm of a constant-returns-toscale CES function. $d$ is an index of global biodiversity, which we assume is determined by the number of species inhabiting the two regions, $s$ and $s^{*}$, respectively. Below, we discuss in more detail the properties of the biodiversity function, $d$. Finally, the function $\omega($.$) indicates the degree$ of a household's preference for biodiversity. It has the standard properties: $\omega^{\prime}>0$ and $\omega^{\prime \prime}<0$. We assume that people in the foreign region have the same utility function (2). Thus, biodiversity is a global public good in this model.

Domestic utility maximization results in the inverse demand functions

$$
\begin{array}{ll}
p(i)=c(i)^{\gamma-1} & \text { for } \quad i \in(0, n), \\
p^{*}(j)=\theta^{-1} m(j)^{\gamma-1} & \text { for } \quad j \in\left(0, n^{*}\right) .
\end{array}
$$

Compared to many other economic-geography models, the demand functions are very simple (e.g., see Baldwin et al. 2003; Fujita et al. 1999 and Neary 2001). They do not contain a CES price index, for example, which is a direct result from specifying the utility function (2) as quasilinear.

Moreover, it is assumed that all varieties are produced with the same technologies and the same factor requirements. Then the prices for these varieties are identical and the arguments $i$ can be dropped. Using (1), (3a), and (3b) in (2) gives the domestic and foreign indirect utility functions, respectively:

$$
\begin{aligned}
& \widetilde{u}=1+y-(1-N) t+\frac{1-\gamma}{\gamma}\left(n p^{\frac{\gamma}{\gamma-1}}+n *\left(\theta p^{*}\right)^{\frac{\gamma}{\gamma-1}}\right)+\omega\left(d\left(s, s^{*}\right)\right) . \\
& \widetilde{u}^{*}=1+y^{*}+N t+\frac{1-\gamma}{\gamma}\left(n^{*} p^{\frac{\gamma}{\gamma-1}}+n(\theta p)^{\frac{\gamma}{\gamma-1}}\right)+\omega\left(d\left(s, s^{*}\right)\right),
\end{aligned}
$$

\section{The producers}

The supply side of the market for the non-numéraire good is characterized by Dixit-Stiglitz monopolistic competition (Dixit and Stiglitz 1977). Assume that each firm produces only one variety of this differentiated good. It is a monopolist in its own market segment but its profits are driven to zero by free market entry and exit. There are fixed costs of production, and thus the number of firms is finite. There is one factor of production and its price, which is exogenous to the firm, is $w$. There is a fixed cost of $F w$ and a constant marginal cost $v w$, where $F$ and $v$ denote technological unit input requirements. If $q(i)$ is the output of domestic firm $i$, its profits are

$$
\pi(i)=p(i) q(i)-(F+v q(i)) w
$$


Ex ante, profits seem to be variable and can be maximized; ex post, they are zero due to free entry and exit of firms.

Since producers have the same cost and demand functions and only differ in the design of the commodity that they produce, we can drop the argument $i$ and consider a representative producer. Profit maximization yields that marginal revenue equals marginal cost:

$$
\not p=v w .
$$

To simplify notation, we invoke a normalization assumption and choose units of the input such that $\gamma=v$. Thus,

$$
p=w
$$

and, by analogy, $p^{*}=w^{*}$ for foreign producers. Using (6) and its foreign analogue in the zeroprofit condition yields:

$$
q=q^{*}=\frac{F}{1-\gamma},
$$

This is a standard result especially for economic geography models using the Dixit/Stiglitz version of monopolistic competition (See Baldwin et al. 2003; Fujita et al. 1999; Neary 2001). With costs being homogeneous of degree 1 in the factor prices, the output of a single variety is determined by the price elasticity and the parameters of the cost function, but it does not depend on any other variables of the model.

Given that each firm produces the same quantity, the number of firms can be inferred from the factor market equilibrium. Let the factor endowments in the two regions be $K$ and $K^{*}$, respectively. As a normalization, $K+K^{*}=1$. As assumed in (5), domestic factor demand is $n(F+v q)$ and by analogy its foreign equivalent is $n *(F+v q)$. Using $\gamma=v$ and (7), the equilibrium conditions for the factor markets are

$$
\begin{aligned}
& n=(1-\gamma) \frac{K}{F}, \\
& n^{*}=(1-\gamma) \frac{1-K}{F} .
\end{aligned}
$$

Using (7) again, we obtain the conditions

$$
Q=n q=K
$$

and

$$
Q^{*}=n^{*} q *=1-K
$$

which will turn out to be very useful in the course of the investigation. 


\section{Goods market equilibrium}

The goods-market equilibrium is determined by the equality of supply and demand, i.e. by

$$
\begin{aligned}
& q=N c+(1-N) \theta m^{*}, \\
& q^{*}=N \theta m+(1-N) c^{*},
\end{aligned}
$$

Using the domestic inverse demand functions, (3a) and (3b), and their foreign equivalents, we obtain

$$
\begin{aligned}
& q=[N+(1-N) \Theta] p^{\frac{1}{\gamma-1}}, \\
& q^{*}=[N \Theta+(1-N)] p^{\frac{1}{\gamma-1}},
\end{aligned}
$$

with $\Theta=\theta^{\frac{\gamma}{\gamma-1}}<1$. This can be solved for the equilibrium prices once (7) is used to substitute for $q$ and $q^{*}$ :

$$
\begin{aligned}
& p=\left[\frac{1-\gamma}{F}(\Theta+N(1-\Theta))\right]^{1-\gamma}, \\
& p^{*}=\left[\frac{1-\gamma}{F}(1-N(1-\Theta))\right]^{1-\gamma},
\end{aligned}
$$

\section{Indirect utility}

Using (10) and (10') to substitute for $p$ and $p^{*}$ and (8) and ( $\left.8^{\prime}\right)$ to substitute for $n$ and $n^{*}$ in (4) and (4') yields

$$
\begin{aligned}
& \tilde{u}=1+y-(1-N) t+\frac{(1-\gamma)^{2-\gamma}}{\gamma F^{1-\gamma}}\left(\frac{K}{(\Theta+N(1-\Theta))^{\gamma}}+\frac{\Theta(1-K)}{(1-N(1-\Theta))^{\gamma}}\right)+\omega\left(d\left(s, s^{*}\right)\right), \\
& \tilde{u}^{*}=1+y^{*}+N t+\frac{(1-\gamma)^{2-\gamma}}{\gamma F^{1-\gamma}}\left(\frac{\Theta K}{(\Theta+N(1-\Theta))^{\gamma}}+\frac{1-K}{(1-N(1-\Theta))^{\gamma}}\right)+\omega\left(d\left(s, s^{*}\right)\right) .
\end{aligned}
$$

\section{Biodiversity}

We close our model by deriving the impacts of economic activity on biodiversity. Assume that there are species $i \in[0, s]$ at home and $i^{*} \in\left[0, s^{*}\right]$ abroad. The total number of species, $s\left(s^{*}\right)$, is used as an index of domestic (foreign) species richness, which is the standard ecological measure used most regularly in ecological-economic modeling (Armsworth et al. 2004; Baumgärtner 
2004). $s$ and $s^{*}$ are very large and will therefore be treated as real numbers in the following analysis.

We adopt a standard assumption from the literature on ecological-economic integrated system modeling and suggest that each species maximizes its net energy (Crocker and Tschirhart 1992; Tschirhart 2000, Pethig and Tschirhart 2001, Eichner and Pethig 2003; Finnoff and Tschirhart 2003 ;). Let $b(i)$ denote the biomass of species $i$ (measured in energy units) and $e(i, b(i), s)$ be the effort (energy) required to maintain biomass $b(i)$, with partial derivatives $e_{b}>0, e_{b b}>0, e_{s}<0$, and $e_{b s}<0$. Increasing marginal cost reflects congestion, i.e. the fact that it becomes increasingly difficult for a species to maintain its biomass if its biomass is already large. The negative impacts of species richness on total and marginal costs indicate that diverse ecosystems function better than more homogeneous ones. See Tilman, Polasky and Lehman (2005), for example. In the foreign region, we have an analogous effort function $e^{*}\left(i^{*}, b^{*}\left(i^{*}\right), s^{*}\right)$. Therefore the following results, derived for the home region, carry over to the foreign region. In the home region, the problem is to maximize $b(i)-e(i, b(i), s)$ with respect to $b$. This results in

$$
e_{b}(i, b(i), s)=1 \text {. }
$$

Total differentiation yields

$$
\frac{d b(i)}{d s}=-\frac{e_{b s}(i, b(i), s)}{e_{b b}(i, b(i), s)}>0
$$

Total biomass, i.e. the integral of all species-specific biomasses, $b(i)$, over the interval $[0, s]$ is limited by carrying capacity, $B$, which depends on factors exogenous to this model, such as climate, suitable species habitats and other environmental conditions. Moreover, carrying capacity is affected by economic activities. In particular, $B$ is a decreasing function of human population size, $N$, and the total output of the manufacturing sector, $n q$, which turns out to equal $K$. See equations (9) and (9'). Thus,

$$
\int_{0}^{s} b(i) d i=B(N, K)
$$

with $B_{L}<0$ and $B_{K}<0$. Moreover, assume that $B(.,$.$) is strictly concave. Total differentiation of$ (12) using Leibniz' rule yields

$$
\begin{aligned}
& \frac{d s}{d N}=\frac{B_{L}}{b(s)+\int_{0}^{s} \frac{d b(i)}{d s} d i}<0, \\
& \frac{d s}{d K}=\frac{B_{K}}{b(s)+\int_{0}^{s} \frac{d b(i)}{d s} d i}<0,
\end{aligned}
$$


where $d b(i) / d s$ is taken from (12). Since the denominators in (13a) and (13b) are unambiguously positive, it follows that increased economic activity will result in both loss of species richness and in the total biomass of each species population. Although (13) and (13b) were derived for the home region, we assume that the same relationships govern economic-ecological interactions in the foreign region.

Recall from (2) that biodiversity is a global public good, and that there is some index, $d$, which measures the current state of global biodiversity. However, because species may be redundant, i.e. the same species may be found in both regions, the global biodiversity index is unlikely to be the sum of the number of species in the two regions. To avoiding the double counting of species that redundancy implies, we assume that the biodiversity index function, $d\left(s, s^{*}\right)$, has the following properties (subscripts denoting partial derivatives):

$$
\begin{aligned}
& d_{s}>0, \quad d_{s^{*}}>0, \quad d_{s s} \geq 0, \quad d_{s^{*} s^{*}} \geq 0, \quad d_{s s^{*}}=d_{s^{*}} \leq 0, \\
& d(s, 0)=s, \quad d\left(0, s^{*}\right)=s^{*}, \quad d\left(s, s^{*}\right) \leq s+s^{*} \text { for } s \neq 0 \text { and } s^{*} \neq 0 .
\end{aligned}
$$

The first-order partial derivatives are self-evident; global biodiversity increases with greater species richness in either region. The cross-partial derivatives are negative since an increase in the number of species in one region raises the probability that an additional species in the other region is redundant. Thus, the larger the absolute value of $d_{s s^{*}}$, the larger is redundancy. In the case of strict endemism, $d_{s s^{*}}$ may be zero. The second own-derivatives, $d_{s s}$ and $d_{s^{*}} *$, are nonnegative. They are zero if the number of species is zero in the other region or if species are stricly endemic. If there is some redundancy and if the number of species in the other region is larger than zero, they are positive. The underlying intuition is as follows: an increase in number of species in one region raises the probability that species in the other region become redundant; however, as this number goes to infinity, this probability approaches a finite value, usually 1 . In other words: if the number of species is large, the probability of redundancy is already very large and cannot be increased much further by adding new species. Thus, the increase in the risk of redundancy is declining in the number of species and, therefore, $d_{s s}>0$ and $d_{s^{*}} *>0$. Redundancy implies that diversity is in general less than the sum of the numbers of species in the two regions, equality only holding in the case of perfect endemism. A special case of the diversity function is the CES function

$$
d\left(s, s^{*}\right)=\left(s^{1+\rho}+s^{* 1+\rho}\right) \frac{1}{1+\rho}
$$

where $\rho \geq 0$ measures the degree of redundancy. It is seen that this function indeed has the properties stated in (14). For $\rho=0$, all species are endemic and $d=s+s^{*}$. For $\rho \rightarrow \infty$, no species is endemic and $d=\max \left(s, s^{*}\right)$ This CES specification of the $d(.,$.$) function serves only as an$ illustration. For the remainder of the paper, we will continue using the general measure of biodiversity, $d\left(s, s^{*}\right)$. 


\section{Agglomeration and Biodiversity: The Case of Immobile Factors of Production}

We start with the scenario in which factors of production are immobile. One might view this as a short-term model with capital being the factor under consideration. Capital is immobile;its owners, however, can move. In a first step, we will consider a laissez-faire situation without government intervention. Then we will look at welfare-maximizing policies for the case of symmetric regions and finally consider the case of asymmetric regions in which the species richness at home and abroad is affected by economic activity differently.

We assume symmetry in the factor endowments, i.e. $K=K^{*}=0.5$. All households have the same factor income, $y$ (or $y^{*}$ for foreign households), which is independent of their region of residence. Since from (6) $w=p$, and by analogy for foreign producers $w^{*}=p^{*}$, we have

$$
y=y^{*}=0.5\left(p+p^{*}\right) .
$$

Moreover, $K=K^{*}=0.5$ implies that the impact of production on biodiversity is constant and identical in both countries.

Let us first consider the laissez-faire case without policies directed at biodiversity conservation. A spatial equilibrium is attained if the indirect utilities in the two regions are equal. Then there are no incentives to migrate. Migration of households does occur if the indirect utilities in the two regions differ:

$$
\widetilde{u}-\widetilde{u}^{*}=-t+\frac{(1-\Theta)(1-\gamma)^{2-\gamma}}{2 \gamma F^{1-\gamma}}\left(\frac{1}{(\Theta+N(1-\Theta))^{\gamma}}-\frac{1}{(1-N(1-\Theta))^{\gamma}}\right) .
$$

where $-t$ is tax paid by domestic citizens, but not paid by foreigners and the second term on the right-hand side is the consumer-surplus differential, which will be denoted CS-CS in what follows. CS-CS is decreasing in N. This is due to a congestion effect. People prefer to live in the less populated region because prices of local goods (that do not contain a transportation cost mark-up) are low if population density, and therefore demand, is low. Moreover, it can be shown that the consumer surplus differential is convex for $N>0.5$ and concave for $N<0.5$. See the appendix for the formal proofs.

Figure 1 represents the indirect-utility differential assuming that the tax rate is positive. The bending line is the consumer surplus differential. Without taxes, there is a unique equilibrium, $E_{0}$, which is stable. The horizontal line represents the tax rate. An increase in the tax rate leads to a leftward shift of the equilibrium, i.e. taxation of domestic citizens to finance transfers given to foreign households causes outward migration. Algebraically: $d N / d t<0$. 


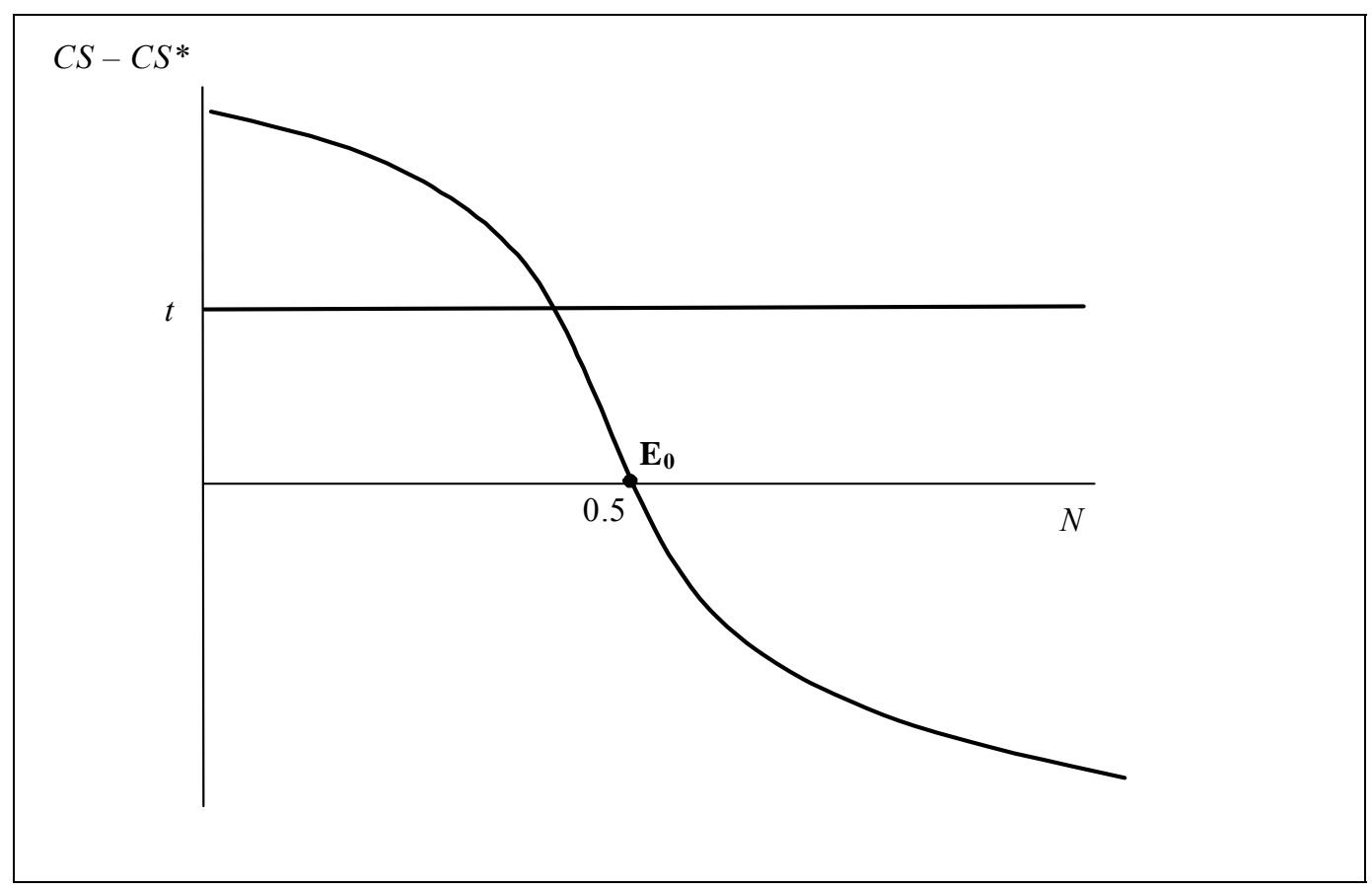

Figure 1: Indirect utility and the migration equilibrium

A benevolent policy maker's objective is to maximize total welfare, $W=N \tilde{u}+(1-N) \tilde{u} *$. Using (11), (11'), $K=K^{*}=0.5$, the fact that $N y+(1-N) y^{*}=0.5\left(p+p^{*}\right)$, employing (10) and (10') to substitute for $p$ and $p^{*}$, and rearranging terms, one can write the welfare functional as

$$
W=1+\frac{(1-\gamma)^{1-\gamma}}{2 \gamma F^{1-\gamma}}\left(\frac{1}{(\Theta+N(1-\Theta))^{\gamma-1}}+\frac{1}{(1-N(1-\Theta))^{\gamma-1}}\right)+\omega\left(d\left(s, s^{*}\right)\right) .
$$

This is maximized with respect to the tax rate, $t$. Note that the impact of the tax rate on welfare, $W$, is always via the population variable, $N$. Since the latter is a monotonic function of $t$, as shown in Figure 1, we can represent the welfare impacts of a change in $t$ by a change in $N$. Thus,

$$
\frac{d W}{d N}=\frac{(1-\Theta)(1-\gamma)^{2-\gamma}}{2 \gamma F^{1-\gamma}}\left(\frac{1}{(\Theta+N(1-\Theta))^{\gamma}}-\frac{1}{(1-N(1-\Theta))^{\gamma}}\right)+\left(d_{s} \frac{d s}{d N}-d_{s^{*}} \frac{d s^{*}}{d N^{*}}\right) \omega^{\prime} .
$$

Using (16), it is seen that the first term on the right-hand side of equation (17) equals $C S$ - $C S^{*}$. If this consumer surplus differential is positive, people migrate to the home region and equation (16) shows that, if biodiversity is neglected for a moment, this enhances welfare. If $C S-C S^{*}$ is negative, migration into the opposite direction is equally welfare-enhancing. Therefore, without consideration of biodiversity, free mobility of residents would establish the socially desirable equilibrium. However, besides income and consumer surplus, biodiversity matters, too. To 
simplify our analysis but with little loss of generality, we assume that $d s / d N=d s * / d N^{*}=-1$. Equation (17) can then be rewritten:

$$
\frac{d W}{d N}=C S-C S^{*}-\left(d_{s}-d_{s^{*}}\right) \omega^{\prime} .
$$

The second term on the right-hand side of (18) represents the effect on global biodiversity. To determine whether $d W / d N=0$ is a condition for a maximum, we take the derivative of (18) with respect to $N$ :

$$
\frac{d^{2} W}{(d N)^{2}}=\frac{d\left(C S-C S^{*}\right)}{d N}+\left(d_{s}-d_{s^{*}}\right)^{2} \omega^{\prime \prime}+\left(d_{s s}-2 d_{s s^{*}}+d_{s^{*} s^{*}}\right) \omega^{\prime} .
$$

As demonstrated in Appendix A.1, the effect of a change in $N$ on the consumer-surplus differential, $\frac{d\left(C S-C S^{*}\right)}{d N}$, is unambiguously negative. Moreover, the second term on the righthand side of eq. (19) is negative, too. These two terms point to an interior optimum. In contrast, $\left(d_{s s}-2 d_{s s^{*}}+d_{s^{*} s^{*}}\right) \omega^{\prime}$ is positive. This means that the second-order condition is not always satisfied and that boundary optima may be optimal, particularly if the degree of redundancy measured by this term is large. This is shown in Figures $2 \mathrm{a}$ to $2 \mathrm{c}$. The solid S-shaped curve represents the marginal consumer surplus and the dotted lines represent the biodiversity term, $\left(d_{s}-d_{s^{*}}\right) \omega^{\prime}$. The biodiversity term, i.e. the negative value of the marginal utility of biodiversity, is subtracted from the marginal consumer surplus in order to arrive at the first-order condition, $d W / d N=0$. See equation (20). Local welfare maxima and minima occur when the two lines intersect. The following cases can be distinguished.

- Case 1. High endemism. The absolute values of second partial derivatives of the $d$ function are small or even zero. In the latter case, the biodiversity line crosses the abscissa with slope zero. In the former case, its slope is negative, but small. The objective function is concave and there is a single interior optimum characterized by an equal distribution of population across the two regions. This is shown in Figure 2a.

- Case 2. High redundancy. In this case, also shown in Figure 2a, the absolute values of the second derivatives of the $d$ function are very large, such that that the biodiversity line is not only negatively sloped, but also steeper than the $C S-C S^{*}$ line. As a result, the objective function is strictly convex and the optimum is a boundary solution in which all the population either lives in one region or in the other. 


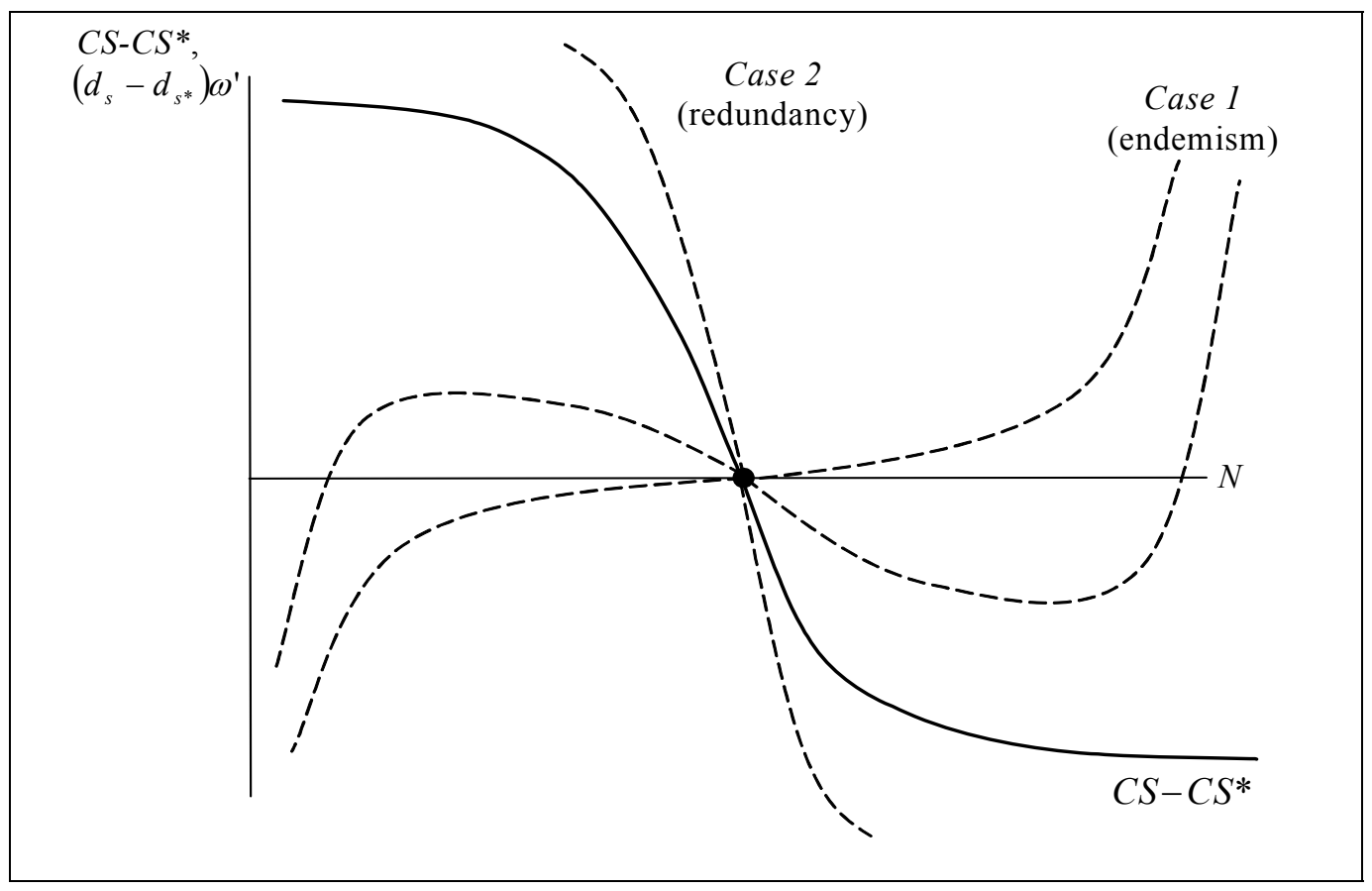

Figure 2a: Characterization of optimum solutions: endemism vs. redundancy

- Case 3. Intermediate case I. In this case, depicted by Figure 2b, the two curves intersect three times. In the center, the biodiversity line is flatter than the consumer-surplusdifferential locus, indicating that this is a local maximum. The biodiversity line is steeper than $C S-C S^{*}$ in its tails and this implies that the other two intersection points are local minima and that the boundary solutions, $N=0$ and $N=1$, are local maxima. Whether the interior or the boundary solutions are optimal, depends on the parameters of the model. Again, a high degree of redundancy favors boundary solutions.

- Case 4. Intermediate case II. Another possibility of local extrema is shown by Figure 2c. Here redundancy dominates when population is equally distributed across the two regions. Thus symmetry cannot be an optimum. However, as biodiversity is diminished in the region that experiences the increase in population density, this loss of biodiversity causes a utility loss which increases more than proportionally. Thus, a concentration of population in one region becomes also undesirable. Therefore, the optima are interior equilibria with asymmetric distribution of population, e.g. such that $20 \%$ of the population live in one region and $80 \%$ in the other. This scenario is possible if there is a large degree of redundancy and, at the same time, the utility function is substantially bent such that large reductions in biodiversity loss lead to more-than-proportional welfare losses. 


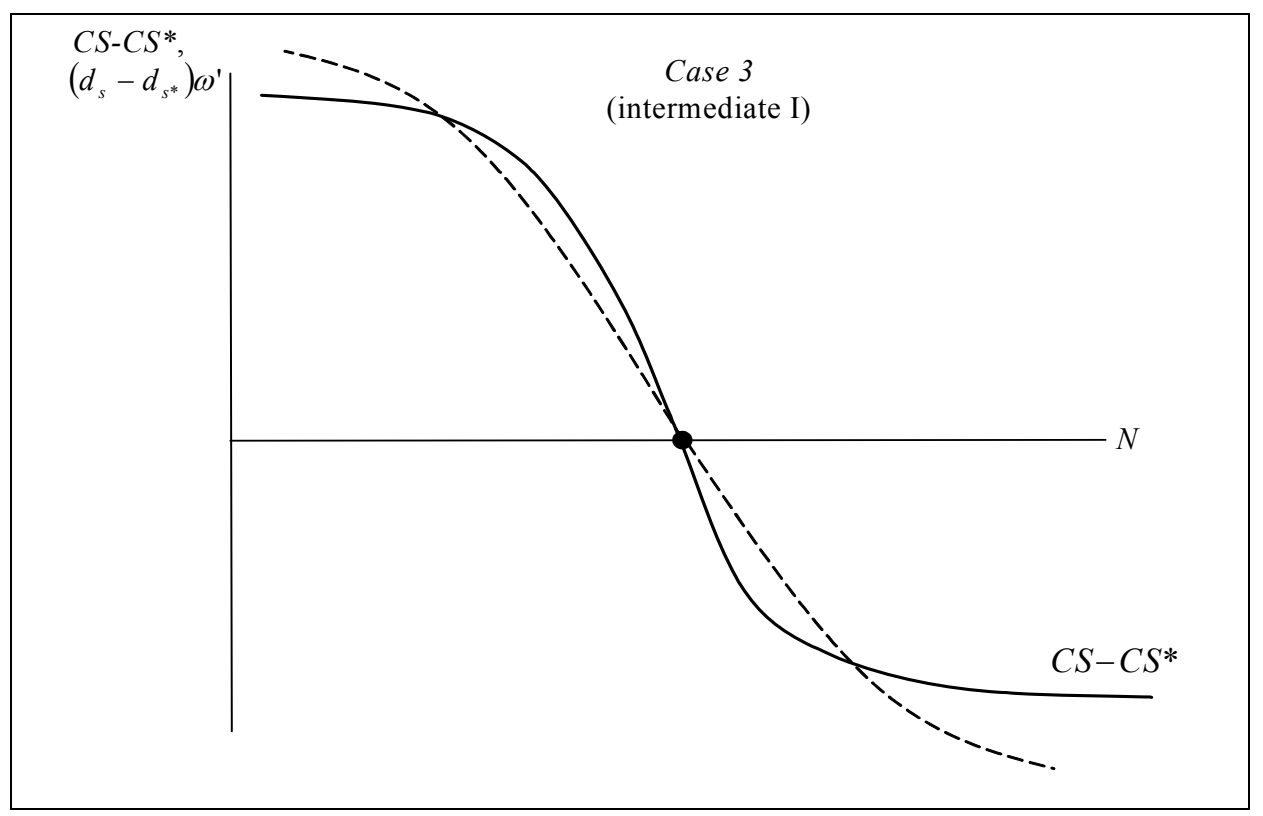

Figure 2b: Characterization of optimum solutions: intermediate case I

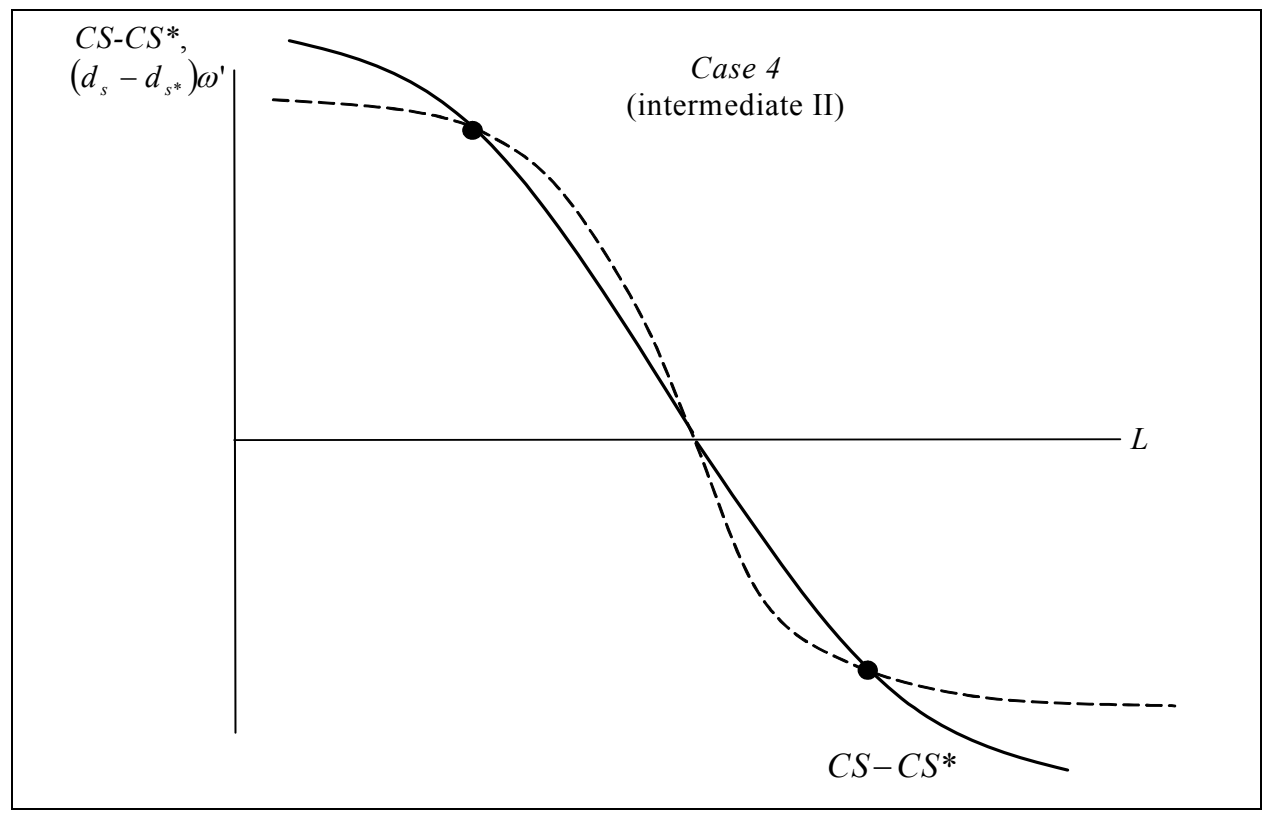

Figure 2c: Characterization of optimum solutions: intermediate case II

These scenarios are intuitive. Without the consideration of biodiversity, people prefer to avoid congestion externalities and do not agglomerate. From the point of biodiversity conservation, however, people should agglomerate if there is a large degree of species redundancy. Some of the species driven to extinction in one region will be preserved in the other region and this 
implies that it is better for biodiversity conservation if people settle on the same spot instead of being dispersed widely geographically. It should be noted, that the dispersion equilibrium, $N=0.5$, is the laissez-faire solution. In order to obtain agglomeration, transfers from one region to the other are necessary. In the case of complete agglomeration, $N=0$ or $N=1$, the tax rates are prohibitive. In terms of natural-habitat conservation, this means that a natural reserve is established, with regulations so strict that activities interfering with species richness are ruled out. In the case of the interior asymmetric optimum, Case 4 in the preceding discussion, the tax rate is less than the prohibitive one. Its optimum level can be determined by setting $d W / d N=0$ in equation (18) and using the fact that the tax rate must be such that the consumer-surplus difference is compensated for, i.e. $t=C S-C S^{*}$. Combining these two conditions gives the tax rate- required to establish the optimum:

$$
t=\left(d_{s}-d_{s^{*}}\right) \omega^{\prime} .
$$

The right-hand side is the marginal environmental damage due to an additional resident. Thus, condition (20) is just a Pigouvian tax rule.

The optima have been derived under the restriction that $d s / d N=d s * / d(1-N)=-1$.. Relaxing this restriction would not change the qualitative result that, depending on the parameters of the model, three types of optima are possible: laissez-faire, prohibitive taxes leading to complete agglomeration, and a moderate tax-transfer scheme that leads to incomplete agglomeration. It makes sense to assume asymmetry. If the ecological system in one region is more vulnerable to human intervention than in the other, $d s / d N$ and $d s * / d(1-N)$ are different. If domestic species richness is affected more drastically by higher population density than foreign species richness, then this shifts the biodiversity line in Figures 2a to 2c upwards. For the intersection points in these figures, this implies that local maxima would be shifted to the left and local minima are shifted to the right. In Case 1, with endemism dominating, the optimum would be characterized by $N<0.5$. The population density in Home must be reduced and this can be achieved by taxes according to equation (20). In the scenarios that produced symmetric optima with partial or complete agglomeration in the preceding investigation (Cases 2 and 4), this would now implies that there is a single optimum with agglomeration in Foreign. The remaining Case 3 would also produce a shift of the optimum towards agglomeration in Foreign, independent of whether the interior solution or one of the boundary solutions is globally optimal in the symmetric case.

\section{Optimal Agglomeration and Biodiversity: The Case of Mobile Capital}

Let us now consider an alternative scenario of mobility: people are mobile like in the preceding section of the paper, but factors are mobile as well. Moreover assume that factors can be separated spatially from their owners. This is the case of mobile capital or, as Baldwin et al. (2003) call it, the footloose-capital model. Compared to the set-up in the previous section of the 
paper, this can be viewed as a long-term scenario in which capital can be moved from one region to the other. As in the previous scenario, factor income is independent of the location of the factors of production. However, in contrast to the preceding part of the paper, the regional allocation of the factors is variable. Thus, we have

$$
y=y^{*}=K p+(1-K) p^{*}
$$

instead of (15).

To analyze the spatial allocation of economic activity, we will first look at the locations of the factors and then at the locations of their owners. Factors move if there is a difference in factor remunerations. From (10) and (10'), we have

$$
w-w^{*}=\left(\frac{1-\gamma}{F}\right)^{1-\gamma}\left((\Theta+N(1-\Theta))^{1-\gamma}-(1-N(1-\Theta))^{1-\gamma}\right)
$$

and it follows that $w>w^{*}$ if $N>1 / 2$. Factors move to where the majority of the consumers live. Factors are indifferent where to locate if $N=0.5$. In Figure 3, this is represented by the vertical line at $N=0.5$. The horizontal parts of the locus are explained by the fact that factor shares cannot be larger than 1 or less than 0 . In a next step, let us consider the behaviour of the factor owners. The difference in utility between East and West is

$$
\tilde{u}-\tilde{u}^{*}=-t+\frac{(1-\Theta)(1-\gamma)^{2-\gamma}}{F^{1-\gamma}}\left(\frac{K}{(\Theta+N(1-\Theta))^{\gamma}}-\frac{1-K}{(1-N(1-\Theta))^{\gamma}}\right) .
$$

Households do not move for particular combinations of $N$ and $K$. For $t=0$, this indifference line is

$$
N=\frac{1}{1-\Theta} \frac{K^{1 / \gamma}-\Theta(1-K)^{1 / \gamma}}{K^{1 / \gamma}+(1-K)^{1 / \gamma}}
$$

This line has a positive slope and it is seen that $N>1$ for $K=1$ and that $N<0$ for $K=0$. Thus, as $N$ can neither be negative nor larger than 1 , the indifference line must have vertical segments at the boundaries of the interval. This is also shown in Figure 3. For the sake of simplicity this indifference line is drawn as a linear locus in the diagram. There are three equilibria: total agglomeration in one of the two regions or an equal distribution of population and factors across the regions. In models with multiple equilibria, the standard method to narrow down the set of equilibria to the feasible ones is to look at adjustment dynamics and stability: unstable equilibria are practically irrelevant and are excluded. Thus, let us consider adjustment dynamics of households and factors. As relocation of factors as well as of households is costly and takes time these adjustments have finite speed. In the diagram, they are depicted by arrows. It is straightforward that the two agglomeration equilibria are stable whereas the symmetric equilibrium is unstable - with the 
notable exception of a saddle path leading to this equilibrium for particular initial conditions. However, as initial conditions are historically given, the probability of starting exactly on this saddle is infinitesimally small. Thus, the corresponding equilibrium is irrelevant and, thus, the mobile-capital model implies agglomeration under conditions of laissez-faire.

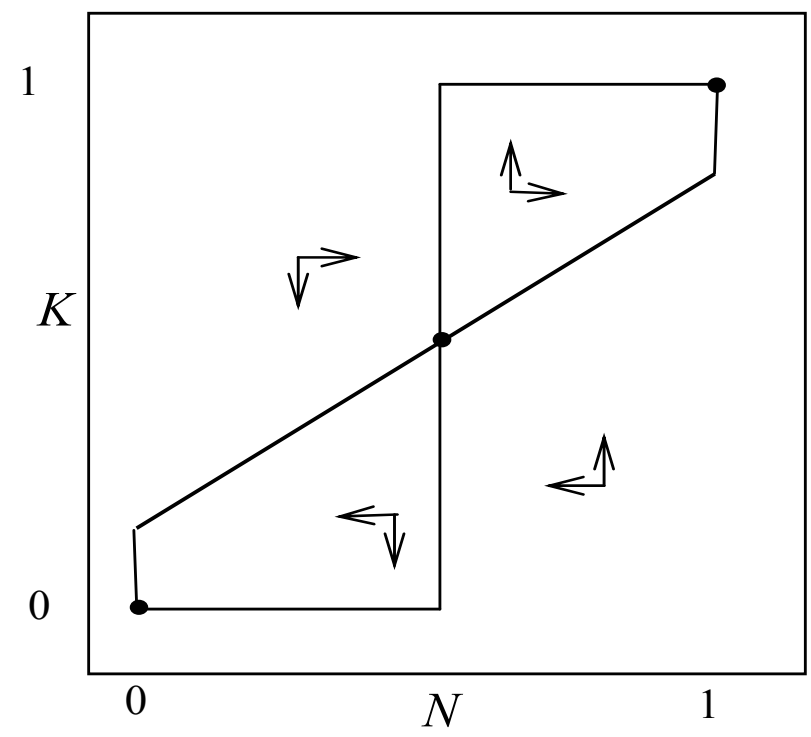

Figure 3: Mobility of factors and of factor owners

Let us now consider welfare maximization. Welfare is

$$
W=1+\frac{(1-\gamma)^{1-\gamma}}{\gamma F^{1-\gamma}}\left(\frac{K}{(\Theta+N(1-\Theta))^{\gamma-1}}+\frac{1-K}{(1-N(1-\Theta))^{\gamma-1}}\right)+\omega(d(s, s *))
$$

and its derivatives with respect to $K$ and $N$ are,

$$
\begin{aligned}
& \frac{d W}{d K}=\frac{(1-\gamma)^{1-\gamma}}{\gamma F^{1-\gamma}}\left(\frac{1}{(\Theta+N(1-\Theta))^{\gamma-1}}-\frac{1}{(1-N(1-\Theta))^{\gamma-1}}\right)+\left(d_{s} \frac{d s}{d K}-d_{s^{*}} \frac{d s^{*}}{d(1-K)}\right) \omega^{\prime} \\
& \frac{d W}{d N}=\frac{(1-\Theta)(1-\gamma)^{2-\gamma}}{\gamma F^{1-\gamma}}\left(\frac{K}{(\Theta+N(1-\Theta))^{\gamma-1}}-\frac{1-K}{(1-N(1-\Theta))^{\gamma-1}}\right)+\left(d_{s} \frac{d s}{d N}-d_{s^{*}} \frac{d s^{*}}{d(1-N)}\right) \omega^{\prime}
\end{aligned}
$$

It is seen that, neglecting biodiversity for a moment, agglomeration is beneficial. (25a) indicates that capital should move to where the consumers are and (25b) implies that consumers should move to where the production takes place. ${ }^{3}$ This is in accordance with the biodiversity objective

3 In particular, we have that the long term in brackets on the right-hand side of equation (24) is 1 in the case of complete agglomeration $(K=N=1$ or $K=N=0),(0.5 \Theta+0.5)^{1-\gamma}$ in the case of dispersion 
if species are redundant. In the case where species are endemic, incomplete agglomeration may be preferable since - depending on the shape of the $\omega$ function, which measures the preference for biodiversity - the cost of large scale extinction of species in one of the two regions may dominate the positive effects of agglomeration to consumers and factor owners. This requires that the government take measures to avoid agglomeration. Taxation of consumers and factors locating in the agglomerating region could be an option. Figure 4 shows how location incentives affect consumers and factor owners. A tax on consumers locating in the home country shifts the indifference line upwards (depicted by the dotted line) such that consumers who were originally indifferent move to the foreign region. By the same argument, the factor owners' indifference locus is shifted to the right if domestic factor incomes are taxed (again depicted by a dotted line). The unstable equilibrium is shifted such that more factors and consumers are located in the home region, implying that the area of the diagram for which the home region is the attractor shrinks.

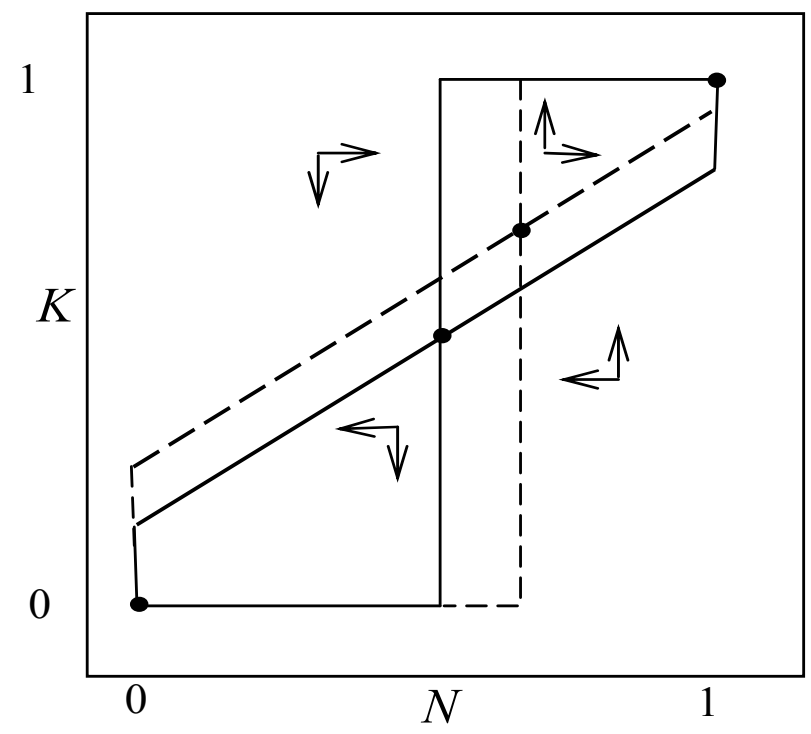

Figure 4: Mobility of factors and of factor owners: the impact of taxes

Figure 4 illustrates that factors of production always tend to agglomerate and that taxes cannot be used to generate a more equal distribution of factors across regions. If biodiversity conservation requires such a distribution, this can only be achieved by command-and-control policies. The underlying reason is that there are no dispersive forces hampering the laissez-faire agglomeration of factors. In the case of consumer location, matters are different. Once the desired allocation of

$(K=N=0.5)$, and $\Theta^{1-\gamma}$ in the case of perfect separation $(K=0, N=1$ or vice versa). It follows that, neglecting biodiversity, welfare is the highest if factors of production and consumers locate in the same region. 
factors is determined by command and control, taxes can be used to give consumers the right incentives to locate. This is depicted in Figure 5. The horizontal line depicts the allocation of factors enforced by command and control regulation. The increasing line is the consumers' indifference locus, which can be affected by the taxes introduced in Section 2. The optimal tax rate can be determined by combining equations (23) and (25b). Setting $d W / d N=0$ in equation (25b) gives the optimality condition that maximizes welfare with respect to the location of consumers for a given allocation of factors. Note that the first term on the right-hand side of (25b) is the consumer-surplus differential, which also occurs in (23). Using this, it follows that

$$
t=-\left(d_{s} \frac{d s}{d N}-d_{s^{*}} \frac{d s^{*}}{d(1-N)}\right) \omega^{\prime},
$$

which is the same condition as (20) if we again assume that the impact of population density on regional species richness is minus unity. The tax is a Pigouvian tax.

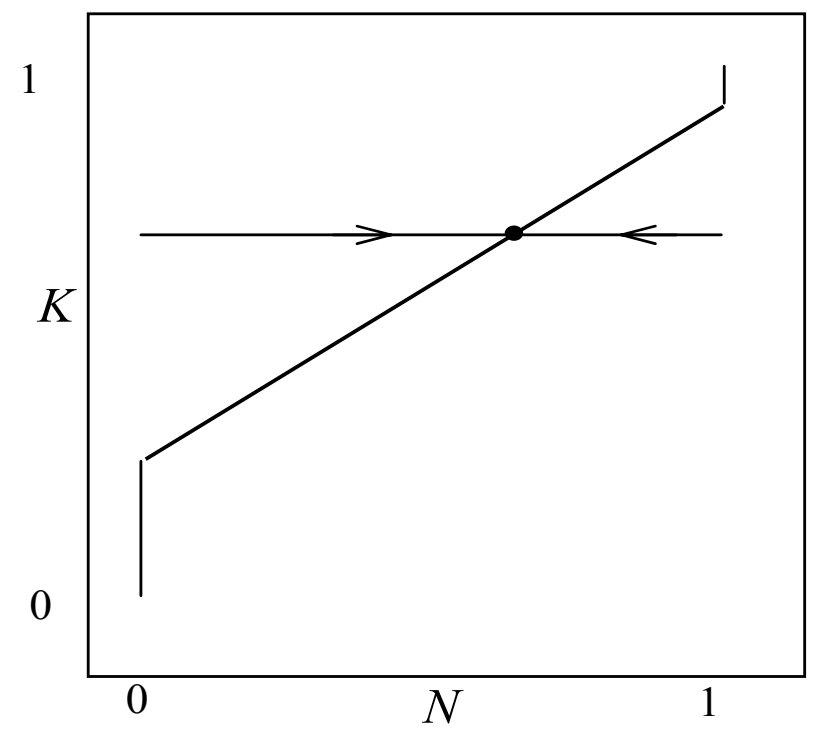

Figure 5: Mobility of factors and of factor owners: combination of command-and-control and taxation

\section{Optimal Agglomeration and Biodiversity: The Case of Mobile Workers}

Let us now consider a third scenario of mobility: people are mobile like in the preceding section of the paper, but they take their factors with them. This is the labor-mobility case. Workers cannot be separated from the factor they supply: when workers move, their factor of production moves with them. Thus,

$$
K=N
$$


i.e. factor supply equals the number of housholds living in a region. Now income is not any more unaffected by the choice of the region of residence: $y=w=p$ and $y^{*}=w^{*}=p^{*}$. Using this in (13) and (13') and employing (12) and (12') to substitute for $p$ and $p^{*}$, respectively, yields

$$
\begin{aligned}
& \tilde{u}=1-(1-N) t+\frac{(1-\gamma)^{1-\gamma}}{\gamma F^{1-\gamma}}\left(\frac{(1-\gamma \Theta) N+\gamma \Theta}{(\Theta+N(1-\Theta))^{\gamma}}+\frac{(1-\gamma) \Theta(1-N)}{(1-N(1-\Theta))^{\gamma}}\right)+\omega\left(d\left(s, s^{*}\right)\right), \\
& \tilde{u}^{*}=1+N t+\frac{(1-\gamma)^{1-\gamma}}{\gamma F^{1-\gamma}}\left(\frac{(1-\gamma) \Theta N}{(\Theta+N(1-\Theta))^{\gamma}}+\frac{(1-\gamma \Theta)(1-N)+\gamma \Theta}{(1-N(1-\Theta))^{\gamma}}\right)+\omega\left(d\left(s, s^{*}\right)\right) .
\end{aligned}
$$

The utility differential is

$$
\tilde{u}-\tilde{u}^{*}=-t+\frac{(1-\gamma)^{1-\gamma}}{\gamma F^{1-\gamma}}\left(\frac{(1-\Theta) N+\gamma \Theta}{(\Theta+N(1-\Theta))^{\gamma}}-\frac{(1-\Theta)(1-N)+\gamma \Theta}{(1-N(1-\Theta))^{\gamma}}\right)
$$

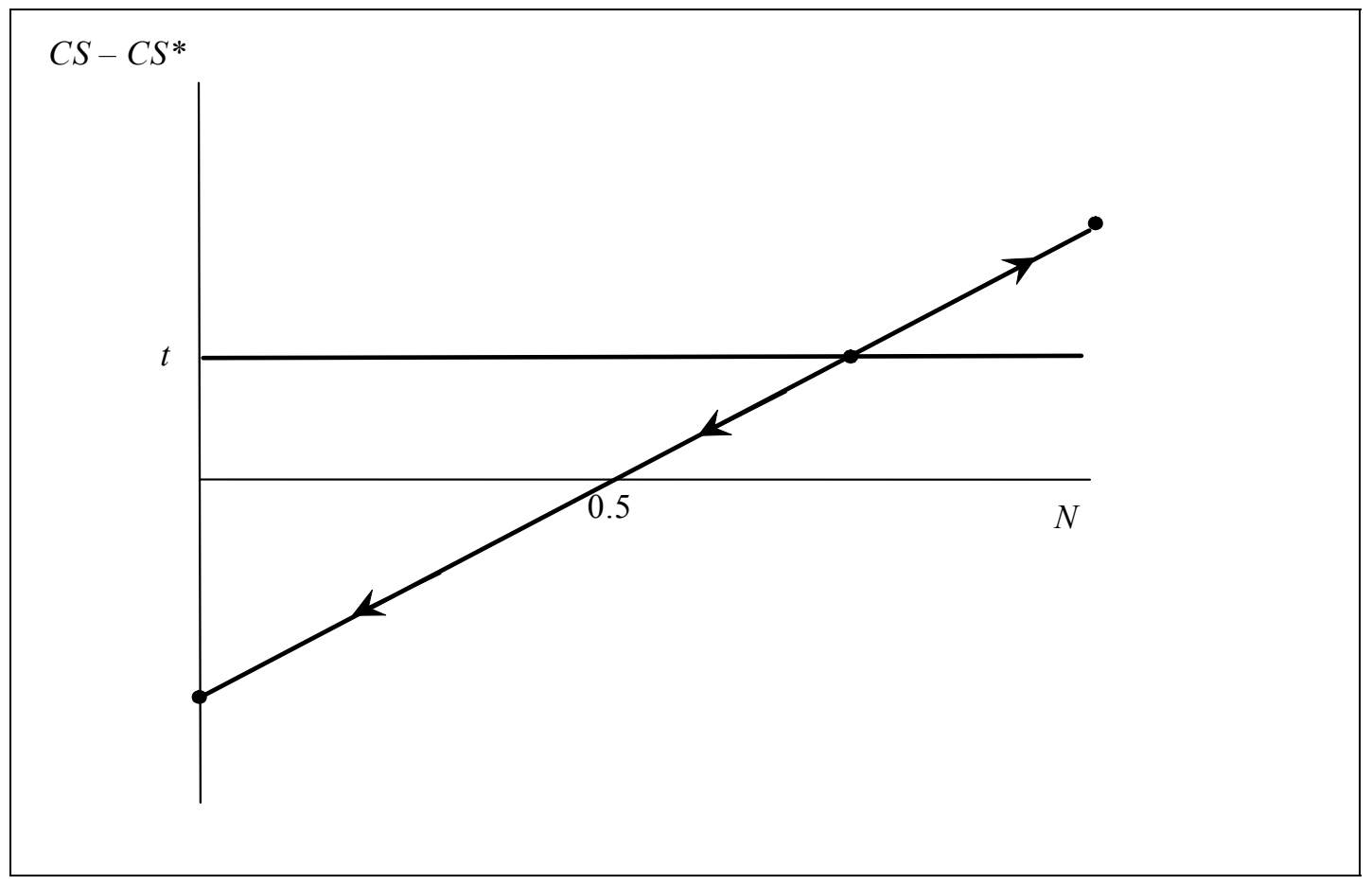

Figure 6: Indirect utility and the migration equilibria in the mobile-workers case

For $t=0$, this differential is zero if $\Theta=1$ and if $N=0.5$. In the former case, $\Theta=1$, the consumer surplus in both regions is identical since with zero transportation costs consumers pay the same prices everywhere and factor prices are identical across regions as well. In the latter case, $N=0.5$, identical population implies that factor supply and final-goods demand are the same in both regions. Appendix A2 shows that the consumer-surplus differential is unambiguously increasing in $N$ such that the symmetric equilibrium $(N=0.5)$ is unstable and the two agglomeration 
equilibria $(N=0$ and $N=1)$ are stable. Figure 6 illustrates this, where the consumer-surplus differential is assumed to be linear for simplicity. The introduction of a tax merely shifts the unstable equilibrium such that the part of the $C S$-CS* line for which the non-taxing region becomes the attractor for mobile workers is increased. It should be noted that other neweconomic-geography models produce different results. In particular, complete agglomeration is the laissez-faire solution only for a limited parameter range. Otherwise symmetric equilibria are stable and for critical parameter values bifurcations occur, which may be tomahawk-shaped like in Fujita et al. (1999) or pitchfork-shaped like in Pflüger (2004).

Welfare, $W$, is $N \widetilde{u}-(1-N) \widetilde{u}^{*}$. From (26) and (26'):

$$
W=1+\frac{(1-\gamma)^{1-\gamma}}{\gamma F^{1-\gamma}}\left(\frac{N}{(\Theta+N(1-\Theta))^{\gamma-1}}+\frac{1-N}{(1-N(1-\Theta))^{\gamma-1}}\right)+\omega\left(d\left(s, s^{*}\right)\right)
$$

and differentiating with respect to $N$ yields

$$
\begin{aligned}
\frac{d W}{d N}= & \frac{(1-\gamma)^{1-\gamma}}{\gamma F^{1-\gamma}}\left(\frac{(2-\gamma)(1-\Theta) N+\Theta}{(\Theta+N(1-\Theta))^{\gamma}}-\frac{(2-\gamma)(1-\Theta)(1-N)+\Theta}{(1-N(1-\Theta))^{\gamma}}\right) \\
& +\left(d_{s}\left(\frac{d s}{d N}-\frac{d s}{d K}\right)-d_{s^{*}}\left(\frac{d s^{*}}{d N^{*}}-\frac{d s^{*}}{d K^{*}}\right)\right) \omega^{\prime}
\end{aligned}
$$

Appendix A.3 shows that the first term on the right-hand side of (29) is increasing such that $d W / d N=0$ minimizes welfare in the absence of biodiversity concerns. The income-andconsumption part of welfare is maximized for $N=0$ and $N=1 .{ }^{4}$

For a graphical representation assume that $d s / d N=d s / d K=d s^{*} / d N^{*}=d s^{*} / d K^{*}=-1$ like in Section 3 of this paper. The second term on the right-hand side of equation (29) then simply is $-2\left(d_{s}-d_{s^{*}}\right) \omega^{\prime}$, which is twice the effect known from the immobile-fators model. The reason is that each migrant now takes her factor with her and this has an additional adverse effect on biodiversity. Figure 6 depicts the marginal effect of a change in $N$ on material well-being, $M M W$, and $2\left(d_{s}-d_{s^{*}}\right) \omega^{\prime}$. If the latter is larger than the former, an increase in $N$ is welfare-deteriorating. Otherwise, it is welfare increasing - unless $M M W=2\left(d_{s}-d_{s^{*}}\right) \omega^{\prime}$, which implies that a local welfare maximum or minimum has been attained. The possible shapes of the marginal value of biodiversity are the same is in Figures 1 and 2 and we depict two cases here. See Figure 7. Case 1 assumes that species are largely endemic.In Case 2 redundancy dominates. In both cases, the symmetric solution, $N=0.5$, is a local minimum. Under dominance of endemism, Case 1, incomplete agglomeration, either at home or abroad, is the optimum. If species are redundant,

4 Note, for example, that the large term in brackets in the welfare functional, equation (28), equals 1 if $N=0$ or if $N=1$ and it equals $(0.5+0.5 \Theta)^{1-\gamma}<1$ if $N=0.5$ 
the boundary solutions of perfect agglomeration are optimal. Since agglomeration is the laissezfaire equilibrium, environmental regulation to affect location decisions is not necessary in that case. Matters are different in case 1: A fraction of the workforce, which wants to locate in one region, has to be motivated to move to the other region. Taxes do not achieve this, because the incentive is either too small or so large that all workers, not only a fraction, wish to move. Thus, command and control is the appropriate type of environmental regulation.

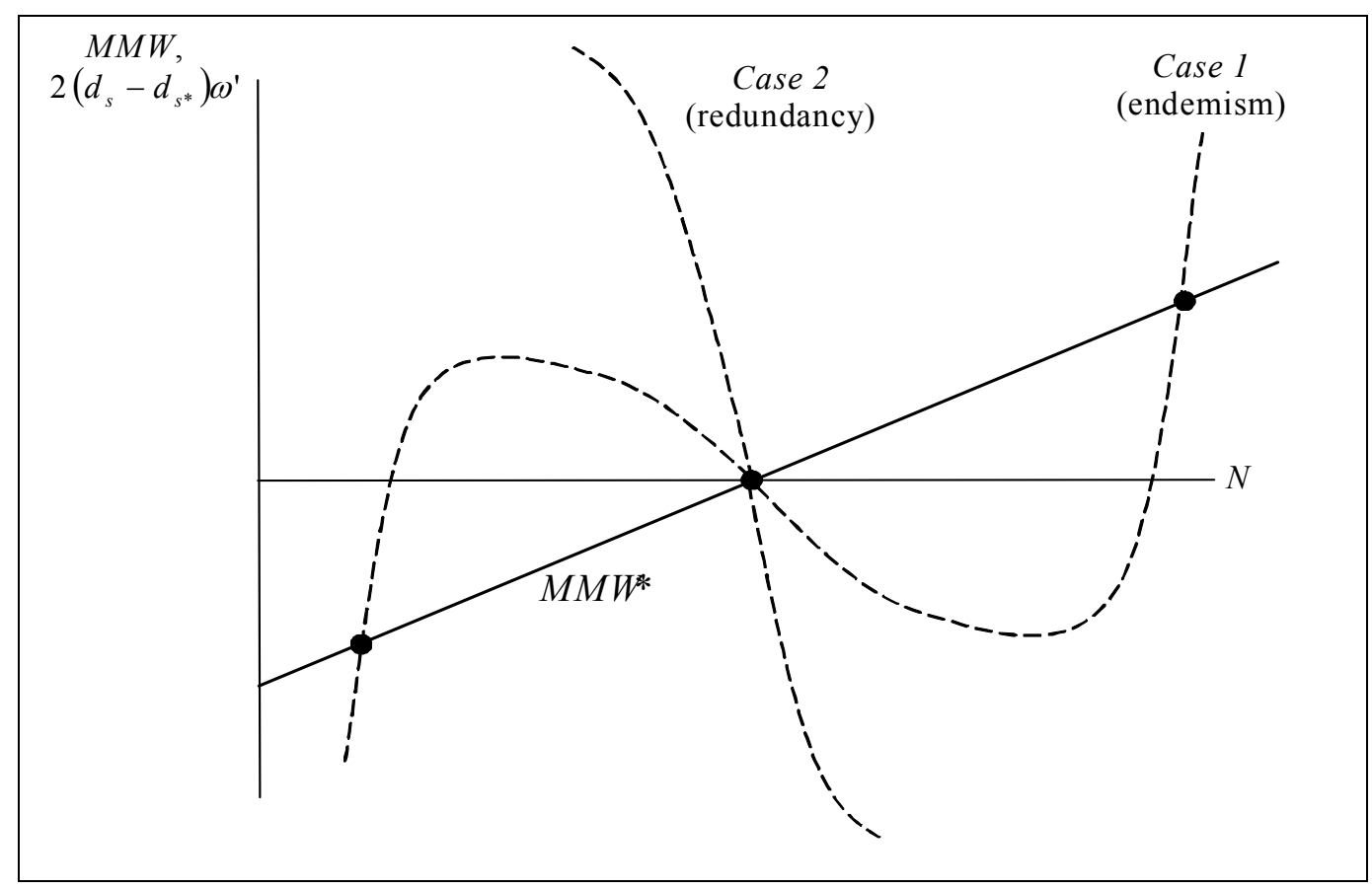

Figure 7: Optimal solutions in the mobile-factors case: endemism vs. redundancy

\section{Summary and conclusions}

In this paper we set out to demonstrate that the new-economic-geography framework for analyzing agglomeration and dispersion of economic activity can be extended to allow for the analogous forces promoting "spreading" or "concentrating" of biological species. The latter effects have long been recognized by ecologists as a key determinant of the spatial distribution of species (e.g., Okubo 2001) but have so far not been incorporated fully in economic-ecological models of biodiversity preservation. By addressing the spatial dimension of economic activity allocation and biodiversity conservation in a new-economic-geography framework, we have shown explicitly the economic and ecological factors that can determine the optimal location and size of nature reserves. Of particular importance in our model is that the centrifugal and centripetal forces of economic geography have their counterparts in the ecological system: endemism 
and redundancy. If centrifugal forces dominate, people do not want to locate too close to each other. This is good for the ecological system if species are largely endemic. If centripetal forces dominate, free migration generates agglomeration. This is beneficial to the ecological system if species are largely redundant. Thus, material and ecological objectives may converge, but there may also be a conflict of interests. In the latter case, the government should intervene. We considered two types of regulation: taxes and command-and-control. Taxes are effective only if centrifugal forces dominate. In this case, interior migration equilibria are stable and taxes can be used to shift an interior equilibrium such that the optimal combination of biodiversity conservation and material well-being is achieved. If centripetal forces dominate, interior equilibria are unstable and boundary equilibria with full agglomeration are the laissez-faire outcome. Taxes do still shift the interior equilibrium, but this equilibrium is now unstable and, thus, irrelevant in practice. The only way to implement the optimum then is command and control.

The model in this paper is based on a number of simplyfying assumptions that do affect the results. In particular we assumed the existence of only one factor of production, a special quasilinear utility function, and a manna-type numéraire good. With these assumptions we were able to derive explicit solutions algebraically whithout taking recourse to numerical calibrations of the model. The approach is limited insofar as we arrive at the conclusion that the agglomeration forces unambiguously dominate in the mobile-workers model. Other models generate different results. In many cases, centrifugal forces dominate over a certain parameter range and one obtains bifurcations typical of core-periphery models such as in Fujita et al. (1999) and Pflüger (2004). Such models may produce a larger variety of interactions between economic and ecological systems. We conjecture however, that the most of the basic conclusions remain the same. Thus, the relationship between centrifugal versus centripetal forces in the economic system and endemism versus redundancy in the ecological system is likely to be unchanged. Moreover, the conclusion that Pigouvian taxes are useful if symmetric equilibria are stable whereas they are ineffective if full agglomeration is stable should carry over to other types of new-economic-geography models.

In sum, a general principle following from our results is that a policy for determining the location of nature preserves needs to take into account the centrifugal-centripetal forces that dominate both economic and ecological systems. For the economic system, these forces are wellknown from the economic geography literature: agglomeration occurs because producers like large markets and consumers like cheap goods; dispersion occurs because people do not like congestion arising from too many consumers creating a high demand for domestic goods that lack the iceberg transport cost. Here we identify similar, but less well known, countervailing effects for the ecological system: greater species richness in a region increases global biodiversity; however, an increase in the number of species in a region also raises the probability 
that species in the other region become redundant. Because the expansion of economic activity affects the spatial distribution of species, it is often assumed that the former is always "bad" for biodiversity conservation. In this paper, we not only show that this assumption is not always valid but also identify the conditions under which analogous centripetal-centrifugal forces in both the ecological and economic systems can influence the correct policy choice for optimal reserve location. We look forward to further advances in applying the new-economic-geography framework to the problem of designing better policies for reconciling biodiversity conservation and regional economic development. 


\section{References}

Armsworth, P.R, B.E. Kendall, F.W. Davis. 2004. An Introduction to Biodiversity Concepts for Environmental Economists. Resource and Energy Economics 26,115-136.

Baldwin, R., R. Forslid P. Martin, G. Ottaviano, F. Robert-Nicoud, 2003, Economic Geography and Public Policy; Princeton: Princeton University Press.

Baumgärtner, S. 2004. Measuring the Diversity of What? And for What Purpose? A Conceptual Comparison of Ecological and Economic Measures of Biodiversity. Working paper. Interdisciplinary Institute for Environmental Economics, University of Heidelberg, Germany.

Bockstael, N., 1996, Modeling Economics and Ecology: The Importance of a Spatial Perspective, American Journal of Agricultural Economics 78 (5), 1168-1180.

Brock, W, A. Xepapadeas, 2006, Optimal Control and Spatial Heterogeneity: Pattern Formation in Economic-Ecological Models. Department of Economics, University of Wisconsin, Working Paper.

Brock, W, A. Xepapadeas. 2003, Valuing Biodiversity from an Economic Perspective: A Unified Economic, Ecological, and Genetic Approach. American Economic Review 93(5), $1597-$ 1614.

Crocker, T.D., J. Tschirhart. 1992. Ecosystems, Externalities and Economies. Environmental and Resource Economics 2,551-567.

Dixit, A., J.E. Stiglitz 1977. Monopolistic Competition and Optimum Product Diversity. American Economic Review 67, 297-308.

Eichner, T., R. Pethig. 2003. Ecosystem and Economy: An Integrated Dynamic General Equilibrium Approach. Working paper, University of Siegen, Germany.

Eichner, T., J. Tschirhart, 2007, Efficient Ecosystem Services and Naturalness in an Ecological/Economic Model, forthcoming in: Environmental and Resource Economics.

Finnoff, D., J. Tschirhart. 2003. Harvesting in an Eight-Species Ecosystem. Journal of Environmental Economics and Management 45, 589-611.

Fujita, M., P. Krugman, A. Venables, 1999, The Spatial Economy, Cambridge:MIT-Press.

Kanbur, R., M. Keen, S. van Wijnbergen, 1995, Industrial Competitiveness, Environmental Regulation, and Direct Foreign Investment, in: I. Goldin, L.A. Winters, eds., The Economics of Sustainable Development, Cambridge: Cambridge University Press, 289-302.

Koskelo, E., M. Ollikainen, 2001, Optimal Private and Public Harvesting under Spatial and Temporal Interdependence. Forest Science 47(4), 484-496.

Krugman, P., 1991, Geography and Trade, Cambridge MA: MIT-Press. 
Metrick, A, M. Weitzman, 1998, Conflicts and Choices in Biodiversity Preservation, Journal of Economic Perspectives 12(3), 21-34.

Neary, P., 2001, Of Hype and Hyperbola: Introducing the New Economic Geography, Journal of Economic Literature 39, 536-561.

Okubo, A., 2001, Introduction: The Mathematics of Ecological Diffusion," in Diffusion and Ecological Problems: Modern Perspectives, ed. by A. Okubo and S. Levin, 2nd Edition, Berlin: Springer.

Pethig, R., J. Tschirhart, 2001, Microfoundations of Population Dynamics, Journal of Bioeconomics 3, 27-49.

Pflüger, M., 2001, Ecological Dumping under Monopolistic Competition, Scandinavian Jounal of Economics 103, 689-706.

Pflüger, M. 2004, A Simple, Analytically Solvable, Chamberlinian Agglomeration Model, Regional Science and Urban Economics 34, 565-573.

Rauscher, M., 2000, Hot Spots, High Smokestacks and the Geography of Pollution, Paper presented at a conference held on the occasion of the 150th anniversary of JohannHeinrich von Thünen's death, Rostock: mimeo.

Samuelson, P.A., 1952, The Transfer Problem and Transportation Costs: The Terms of Trade When Impediments Are Absent, Economic Journal 62, 278-304.

Sanchrico, J., J. Wilen. 2005. Managing Renewable Resource Use with Market-Based Instruments: Matching Policy Scope to Ecosystem Scale. Journal of Environmental Economics and Management, 50(1), 23-46.

Siebert, H., 1985, Spatial Aspects of Environmental Economics, in: A.V. Kneese, J.L. Sweeney, eds., Handbook of Environmental and Energy Economics. Amsterdam: North-Holland, 125-164.

Smith, M, J. Sanchirico, J.Wilen, 2007, The Economics of Spatial-Dynamic Processes: Applications to Renewable Resources. Resources for the Future, Draft Discussion Paper, Washington DC, February.

Tilman, D.; Polasky, S.; Lehman, C. 2005. Diversity, Productivity and Temporal Stability in the Economies of Humans and Nature. Journal of Environmental Economics and Management 49, 405-426.

Tschirhart, J. 2000. General Equilibrium of an Ecosystem. Journal of Theoretical Biology 203,13-32.

von Thünen, J.H., 1842, Der isolierte Staat in Beziehung auf Landwirtschaft und Nationalökonomie, Aalen: Scientia (Neudruck nach der Ausgabe letzter Hand, 5. Auflage, 1990). 


\section{Appendix}

\section{A.1 Effects of Changes in $N$ on $C S-C S *$ in the Fixed-Factors Model}

Taking first and second derivatives of the second term on the right-hand side in equation (16) yields

$$
\begin{aligned}
& \frac{d\left(C S-C S^{*}\right)}{d N}=\frac{(1-\Theta)^{2}(1-\gamma)^{2-\gamma}}{F^{1-\gamma}}\left(\frac{1}{(\Theta+N(1-\Theta))^{\gamma+1}}-\frac{1}{(1-N(1-\Theta))^{\gamma+1}}\right), \\
& \frac{d^{2}\left(C S-C S^{*}\right)}{(d L)^{2}}=(1+\gamma)(1-\Theta)^{3}(1-\gamma)^{2-\gamma}\left(\frac{F^{\gamma-1}}{(\Theta+L(1-\Theta))^{\gamma+2}}-\frac{F^{\gamma-1}}{(1-L(1+\Theta))^{\gamma+2}}\right) .
\end{aligned}
$$

Thus, $\left(C S-C S^{*}\right)$ is concave if $N>1 / 2$ and convex if $N<1 / 2$.

\section{A.2 Effects of Changes in $N$ on CS-CS* in the Mobile-Workers Model}

The consumer-surplus differential is the complex term on the right-hand side of equation (26)

$$
\frac{d\left(C S-C S^{*}\right)}{d N}=\frac{(1-\Theta)(1-\gamma)^{1-\gamma}}{\gamma F^{1-\gamma}}\left(\frac{(1-\gamma)(1-\Theta) N+\left(1-\gamma^{2}\right) \Theta}{(\Theta+N(1-\Theta))^{\gamma+1}}+\frac{(1-\gamma)(1-\Theta)(1-N)+\left(1-\gamma^{2}\right) \Theta}{(1-N(1-\Theta))^{\gamma+1}}\right) \text {. }
$$

This is unambiguously positive.

\section{A.3 Effects of Changes in $N$ on Marginal Welfare in the Mobile-Workers Model}

Differentiation of (29) with respect to $N$ yields

$$
\begin{aligned}
\frac{d^{2} W}{(d N)^{2}}= & \frac{(1-\Theta)(1-\gamma)^{2-\gamma}}{\gamma F^{1-\gamma}}\left(\frac{(2-\gamma)(1-\Theta) N+2 \Theta}{(\Theta+N(1-\Theta))^{\gamma+1}}+\frac{(2-\gamma)(1-\Theta)(1-N)+2 \Theta}{(1-N(1-\Theta))^{\gamma+1}}\right) \\
& +\frac{d^{2} \omega\left(s(N, K), s^{*}\left(N^{*}, K^{*}\right)\right.}{(d N)^{2}}
\end{aligned}
$$

The long term in brackets on the right-hand side is unambiguously positive. 


\section{CESifo Working Paper Series}

(for full list see www.cesifo-group.de)

1956 Panu Poutvaara and Lars-H. R. Siemers, Smoking and Social Interaction, March 2007

1957 Stephan Danninger and Fred Joutz, What Explains Germany's Rebounding Export Market Share?, March 2007

1958 Stefan Krasa and Mattias Polborn, Majority-efficiency and Competition-efficiency in a Binary Policy Model, March 2007

1959 Thiess Buettner and Georg Wamser, Intercompany Loans and Profit Shifting Evidence from Company-Level Data, March 2007

1960 Per Pettersson-Lidbom and Mikael Priks, Behavior under Social Pressure: Empty Italian Stadiums and Referee Bias, April 2007

1961 Balázs Égert and Carol S. Leonard, Dutch Disease Scare in Kazakhstan: Is it real?, April 2007

1962 Paul De Grauwe and Pablo Rovira Kaltwasser, Modeling Optimism and Pessimism in the Foreign Exchange Market, April 2007

1963 Volker Grossmann and Thomas M. Steger, Anti-Competitive Conduct, In-House R\&D, and Growth, April 2007

1964 Steven Brakman and Charles van Marrewijk, It's a Big World After All, April 2007

1965 Mauro Ghinamo, Paolo M. Panteghini and Federico Revelli, FDI Determination and Corporate Tax Competition in a Volatile World, April 2007

1966 Inés Macho-Stadler and David Pérez-Castrillo, Optimal Monitoring to Implement Clean Technologies when Pollution is Random, April 2007

1967 Thomas Eichner and Ruediger Pethig, Efficient $\mathrm{CO}_{2}$ Emissions Control with National Emissions Taxes and International Emissions Trading, April 2007

1968 Michela Redoano, Does Centralization Affect the Number and Size of Lobbies?, April 2007

1969 Christian Gollier, Intergenerational Risk-Sharing and Risk-Taking of a Pension Fund, April 2007

1970 Swapan K. Bhattacharya and Biswa N. Bhattacharyay, Gains and Losses of India-China Trade Cooperation - a Gravity Model Impact Analysis, April 2007

1971 Gerhard Illing, Financial Stability and Monetary Policy - A Framework, April 2007 
1972 Rainald Borck and Matthias Wrede, Commuting Subsidies with two Transport Modes, April 2007

1973 Frederick van der Ploeg, Prudent Budgetary Policy: Political Economy of Precautionary Taxation, April 2007

1974 Ben J. Heijdra and Ward E. Romp, Retirement, Pensions, and Ageing, April 2007

1975 Scott Alan Carson, Health during Industrialization: Evidence from the $19^{\text {th }}$ Century Pennsylvania State Prison System, April 2007

1976 Andreas Haufler and Ian Wooton, Competition for Firms in an Oligopolistic Industry: Do Firms or Countries Have to Pay?, April 2007

1977 Eckhard Janeba, Exports, Unemployment and the Welfare State, April 2007

1978 Gernot Doppelhofer and Melvyn Weeks, Jointness of Growth Determinants, April 2007

1979 Edith Sand and Assaf Razin, The Role of Immigration in Sustaining the Social Security System: A Political Economy Approach, April 2007

1980 Marco Pagano and Giovanni Immordino, Optimal Regulation of Auditing, May 2007

1981 Ludger Woessmann, Fundamental Determinants of School Efficiency and Equity: German States as a Microcosm for OECD Countries, May 2007

1982 Bas Jacobs, Real Options and Human Capital Investment, May 2007

1983 Steinar Holden and Fredrik Wulfsberg, Are Real Wages Rigid Downwards?, May 2007

1984 Cheng Hsiao, M. Hashem Pesaran and Andreas Pick, Diagnostic Tests of Cross Section Independence for Nonlinear Panel Data Models, May 2007

1985 Luis Otávio Façanha and Marcelo Resende, Hierarchical Structure in Brazilian Industrial Firms: An Econometric Study, May 2007

1986 Ondřej Schneider, The EU Budget Dispute - A Blessing in Disguise?, May2007

1987 Sascha O. Becker and Ludger Woessmann, Was Weber Wrong? A Human Capital Theory of Protestant Economic History, May 2007

1988 Erkki Koskela and Rune Stenbacka, Equilibrium Unemployment with Outsourcing and Wage Solidarity under Labour Market Imperfections, May 2007

1989 Guglielmo Maria Caporale, Juncal Cunado and Luis A. Gil-Alana, Deterministic versus Stochastic Seasonal Fractional Integration and Structural Breaks, May 2007

1990 Cláudia Costa Storti and Paul De Grauwe, Globalization and the Price Decline of Illicit Drugs, May 2007 
1991 Thomas Eichner and Ruediger Pethig, Pricing the Ecosystem and Taxing Ecosystem Services: A General Equilibrium Approach, May 2007

1992 Wladimir Raymond, Pierre Mohnen, Franz Palm and Sybrand Schim van der Loeff, The Behavior of the Maximum Likelihood Estimator of Dynamic Panel Data Sample Selection Models, May 2007

1993 Fahad Khalil, Jacques Lawarrée and Sungho Yun, Bribery vs. Extortion: Allowing the Lesser of two Evils, May 2007

1994 Thorvaldur Gylfason, The International Economics of Natural Resources and Growth, May 2007

1995 Catherine Roux and Thomas von Ungern-Sternberg, Leniency Programs in a Multimarket Setting: Amnesty Plus and Penalty Plus, May 2007

1996 J. Atsu Amegashie, Bazoumana Ouattara and Eric Strobl, Moral Hazard and the Composition of Transfers: Theory with an Application to Foreign Aid, May 2007

1997 Wolfgang Buchholz and Wolfgang Peters, Equal Sacrifice and Fair Burden Sharing in a Public Goods Economy, May 2007

1998 Robert S. Chirinko and Debdulal Mallick, The Fisher/Cobb-Douglas Paradox, Factor Shares, and Cointegration, May 2007

1999 Petra M. Geraats, Political Pressures and Monetary Mystique, May 2007

2000 Hartmut Egger and Udo Kreickemeier, Firm Heterogeneity and the Labour Market Effects of Trade Liberalisation, May 2007

2001 Andreas Freytag and Friedrich Schneider, Monetary Commitment, Institutional Constraints and Inflation: Empirical Evidence for OECD Countries since the 1970s, May 2007

2002 Niclas Berggren, Henrik Jordahl and Panu Poutvaara, The Looks of a Winner: Beauty, Gender, and Electoral Success, May 2007

2003 Tomer Blumkin, Yoram Margalioth and Efraim Sadka, Incorporating Affirmative Action into the Welfare State, May 2007

2004 Harrie A. A. Verbon, Migrating Football Players, Transfer Fees and Migration Controls, May 2007

2005 Helmuth Cremer, Jean-Marie Lozachmeur and Pierre Pestieau, Income Taxation of Couples and the Tax Unit Choice, May 2007

2006 Michele Moretto and Paolo M. Panteghini, Preemption, Start-Up Decisions and the Firms' Capital Structure, May 2007 
2007 Andreas Schäfer and Thomas M. Steger, Macroeconomic Consequences of Distributional Conflicts, May 2007

2008 Mikael Priks, Judiciaries in Corrupt Societies, June 2007

2009 Steinar Holden and Fredrik Wulfsberg, Downward Nominal Wage Rigidity in the OECD, June 2007

2010 Emmanuel Dhyne, Catherine Fuss, Hashem Pesaran and Patrick Sevestre, Lumpy Price Adjustments: A Microeconometric Analysis, June 2007

2011 Paul Belleflamme and Eric Toulemonde, Negative Intra-Group Externalities in TwoSided Markets, June 2007

2012 Carlos Alós-Ferrer, Georg Kirchsteiger and Markus Walzl, On the Evolution of Market Institutions: The Platform Design Paradox, June 2007

2013 Axel Dreher and Martin Gassebner, Greasing the Wheels of Entrepreneurship? The Impact of Regulations and Corruption on Firm Entry, June 2007

2014 Dominique Demougin and Claude Fluet, Rules of Proof, Courts, and Incentives, June 2007

2015 Stefan Lachenmaier and Horst Rottmann, Effects of Innovation on Employment: A Dynamic Panel Analysis, June 2007

2016 Torsten Persson and Guido Tabellini, The Growth Effect of Democracy: Is it Heterogenous and how can it be Estimated?, June 2007

2017 Lorenz Blume, Jens Müller, Stefan Voigt and Carsten Wolf, The Economic Effects of Constitutions: Replicating - and Extending - Persson and Tabellini, June 2007

2018 Hartmut Egger and Gabriel Felbermayr, Endogenous Skill Formation and the Source Country Effects of International Labor Market Integration, June 2007

2019 Bruno Frey, Overprotected Politicians, June 2007

2020 Jan Thomas Martini, Rainer Niemann and Dirk Simons, Transfer Pricing or Formula Apportionment? Tax-Induced Distortions of Multinationals' Investment and Production Decisions, June 2007

2021 Andreas Bühn, Alexander Karmann and Friedrich Schneider, Size and Development of the Shadow Economy and of Do-it-yourself Activities in Germany, June 2007

2022 Michael Rauscher and Edward B. Barbier, Biodiversity and Geography, June 2007 